\title{
REAL-TIME MONITORING AND FORECASTING OF DIKE STRENGTH
}

\author{
M. PONZIANI \& D. BACHMANN \\ Deltares, the Netherlands.
}

\begin{abstract}
Real-time monitoring and forecasting provides useful information in early warning situations for emergency response as part of a modern (flood) risk management. This paper presents a case study of a coastal dike line, where multiple sensors are installed to measure in real-time the water level outside and inside the dike. The dike stability is calculated based on the inputs of the phreatic line and on the schematization of the subsoil. The resulting safety factor is a direct assessment of the dike strength in real-time. For a prediction of the dike performance, fragility curves are derived within a model-based probabilistic analysis for different failure mechanisms: overflow, wave overtopping, wave impact, wave erosion, piping, micro- and macro-stability are considered. They are combined in one overall fragility curve that represents the total probability of failure per dike cross-section as a function of the water level. By combining forecasted water levels and fragility curves, it is possible to get a prediction of the dike reliability. The two workflows of real-time monitoring and forecasting of dike strength are being integrated into the FEWS-DAM Live software system. This allows for the visualization of real-time and historical data of dike stability and probability of failures based on the forecasted water levels. The generated results provide precise information for the emergency response, such as location, timing and probability of failure of specific sections of the flood defense line. With the help of this information, emergency measures that apply to the flood defense line (e.g. starting from increased inspection intervals up to temporally dike enforcement) can be operationally planned, adapted to the situation and triggered. Keywords: dike strength, failure probability, forecasting, fragility curve, monitoring.
\end{abstract}

\section{INTRODUCTION}

An early warning system for dike stability is a complex system that involves sensors installation, data processing, computations and interpretation of the real-time results to support decisions and strategies concerning prevention, protection and emergency response. Previous studies showed the importance and effectiveness of data collected from dike through sensor networks. Data of pore-pressure sensors installed in a dike have been used to simulate the porous flow through the dike and for stability analysis [1]. Sensor networks to measure pore pressure, inclination and temperature proved to be useful to detect leakage of the Rhine levee [2]. Also, finite element models based on sensors data of tidal fluctuations of river level, pore pressure and temperature inside the levee have been used to assess the real-time stability of the Boston levee [3].

A model-based forecast of dike stability combines the forecast of water level at the dike with the strength properties of the dike. It consists of a chain of several models with data sequentially given from one model to the next one. For flood forecasting, the chain starts with a meteorological model predicting the amount and spatial distribution of precipitation, wind and temperature over time. The next step depends on the area considered. In case of riverine regions, a hydrological model calculates the discharge in a river and a hydrodynamic model 
predicts the water level. For coastal regions, a storm surge model is applied to forecast water levels, wave heights and wind set-up. In the last step, water levels and/or wave heights at the dike sections are combined with parameters of the dike strength to predict the dike stability over time. In the last decades, several model-based flood forecasting and alert systems have been applied on a national and on a basin scale [4-6]. However, these systems are restricted to the forecast of discharges and water levels.

This paper presents a study case where real-time monitoring and forecasting of dike strength are combined and integrated in a software system. This system provides crucial information for interventions both during emergency and operational situations.

\section{CASE STUDY: GRONINGEN LEVEES}

The Ommelanderzeedijk is a primary dike in the region of Groningen (North of the Netherlands) that protects the inland from floods of the North Sea. By law, all dikes in the Netherlands must satisfy determined requirements of safety for different failure mechanisms. The program Flood Control 2015 was activated in the area with the aim of improving the water security by including new model computations, a dike strength monitoring system, and dashboards to support crisis management [7]. Within the framework of the monitoring project LiveDijk XL Noorderzijlvest, seven cross-sections of the Ommelanderzeedijk were equipped with water pressure sensors to provide real-time information of the phreatic level inside the dike. A sensor monitoring system is a helpful tool to assess the strength of a dike. It can be used for the safety control of the most critical sections of the dikes until they are improved, to provide information of the dike strength during works of reinforcement, and to monitor the dike sections after improvement. Figure 1 shows the location of the cross-sections along the dike line equipped with sensors. For each cross-section, a schematization of

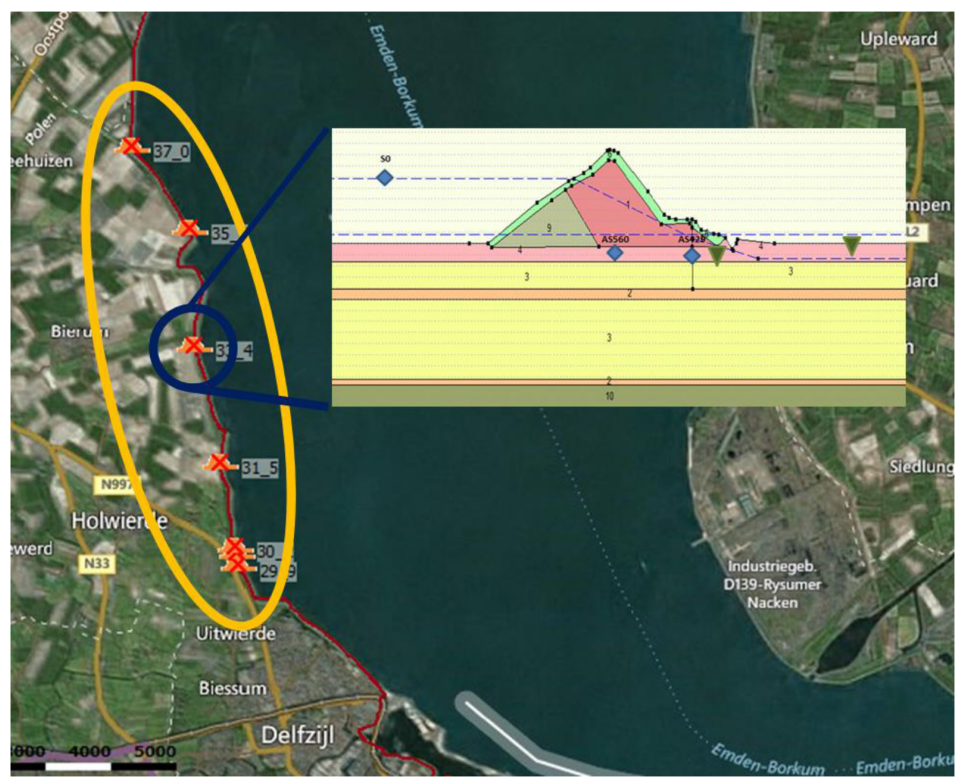

Figure 1: The location of the cross-sections along the dike line and the corresponding subsoil schematization with soil layers, sensors (blue diamonds), fixed water levels (green triangles), and phreatic lines. 
the dike profile and the subsoil was realized including the geo-mechanical properties of each soil layer.

\section{METHODS}

\subsection{Real-time measurements and stability assessment}

The measurements recorded by the sensors (see Fig. 1) are transferred to the Dijk Data Service Centrum (DDSC) [8], which is a platform created around a National database to store and to provide access to sensor data for dikes. It is thus possible to have access of both realtime and historical data. Data of the sensors from the seven cross-sections of the Ommelanderzeedijk are imported hourly in the FEWS-DAM Live Software system to perform a calculation of dike stability for each cross-section. The inputs for the stability calculations are the phreatic line, the subsoil schematization including the geo-mechanical properties of each layer and the model parameters. The phreatic line is built with values of water levels measured by the sensors and other fixed water levels that can be provided in the schematization (e.g. the polder level). In this study, the stability calculation is performed by DAM Live using the slope stability model of Bishop [9]. The method considers circular sliding surfaces to determine the slip circle with the lowest safety factor, which represents the ratio between the maximum load that the dike can sustain and the actual load applied to the dike. For each cross-section the output of the calculation is thus a safety factor and a drawing of the critical circle of Bishop on the dike schematization including the phreatic line obtained with the sensor measurements. The system is flexible in the use and applicability of the models and source data. It is thus possible to perform the stability calculations with different models and to update the input values (e.g. modify soil properties or add water levels).

\subsection{Forecasting of dike performance}

The forecast of the dike strength is expressed in terms of a probability of failure of the dike over a forecasted time span (failure probability time series). This time series is determined by a reliability transformation, in which the water levels are transformed via a pre-calculated fragility curve into probabilities for each time step, as shown in Fig. 2. This transformation requires a very low computational time and therefore it is suitable for forecasting.

A fragility curve represents the probability of failure of the dike as a function of the outside water level. The use of fragility curves has been applied to flood management systems since 1991 [10] and for strategic flood risk assessments in the latest years [11-13]. Further developments in the methods of determining fragility curves [14], the intrinsic level of detail [15] and their integration into flood risk assessment models [16-18] have been researched and expanded since their conception. Trends show also an increase in the application of fragility curves for assessing operational reliability [19]. For example, Bachmann et al. [20] use precalculated fragility curves for 60 dike sections of the river Emscher to integrate also probabilistic aspects of dike failure into a flood forecasting system.

To generate fragility curves for the presented case study, the reliability analysis of the modular software package ProMAIDEs (Protection Measure against Inundation Decision Support) was used [21]. A model-based probabilistic analysis includes in general three steps. The first step is the configuration of a deterministic model derived from an analysis of the structure to determine the failure mechanisms of the system. The following failure mechanisms were 


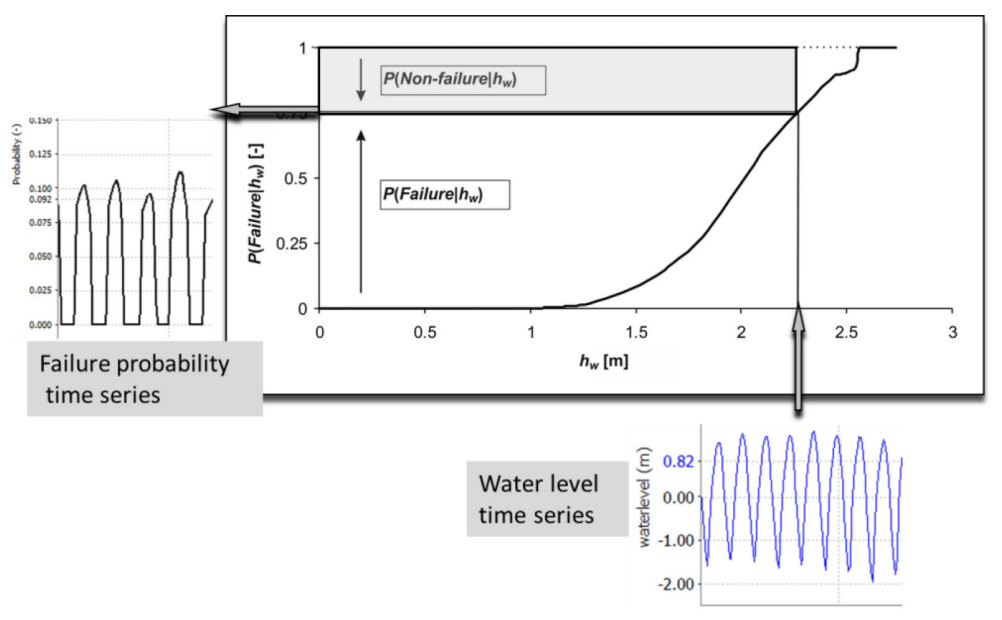

Figure 2: Concept of fragility curve and reliability transformation.

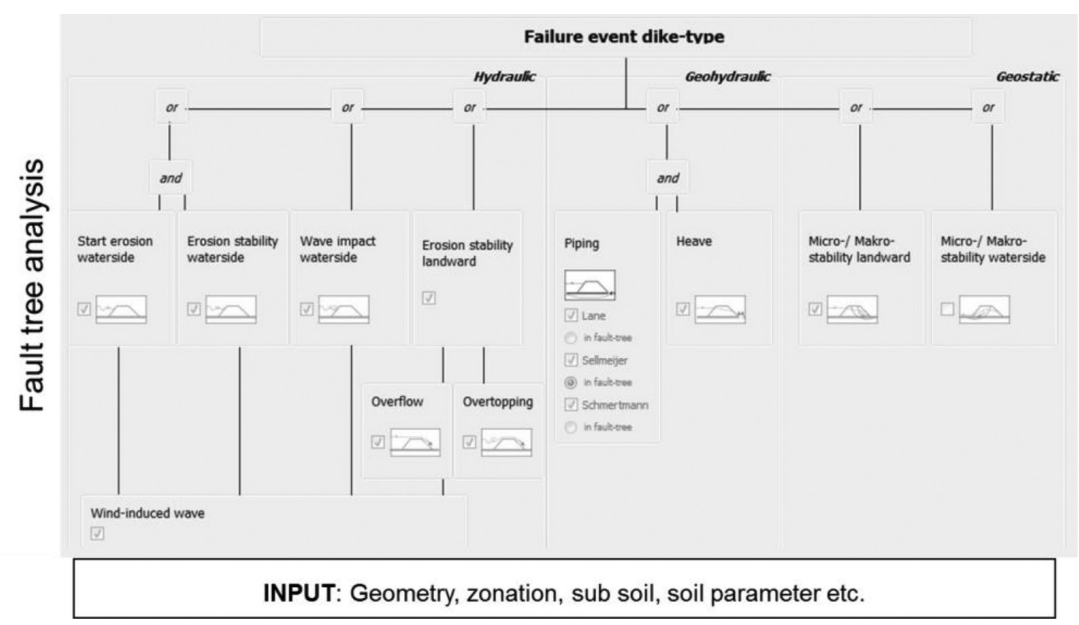

Figure 3: Fault tree analysis and input parameters for a dike cross-section implemented in ProMaIDes.

considered for this study: overflow, wave overtopping, wave impact, wave erosion, piping in combination with heave, micro- and macro-stability of the landward slope. A fault tree analysis is used to structure these mechanisms leading to a dike failure, as shown in Fig. 3.

The second step is a statistical description of the input variables, which are characterized by their mean values, standard deviations and distribution types. The assumption is that all properties are homogeneous within a soil layer. The available input variables for this study are the subsoil schematization of each dike profile and the mean values of soil properties for each layer (cohesion, friction angle, and density). These were obtained from the available geotechnical data. Missing mean values (e.g. resistance of the water side slope against waves) were derived by expert judgment. The required statistical moments and distributions types are based on literature values. 


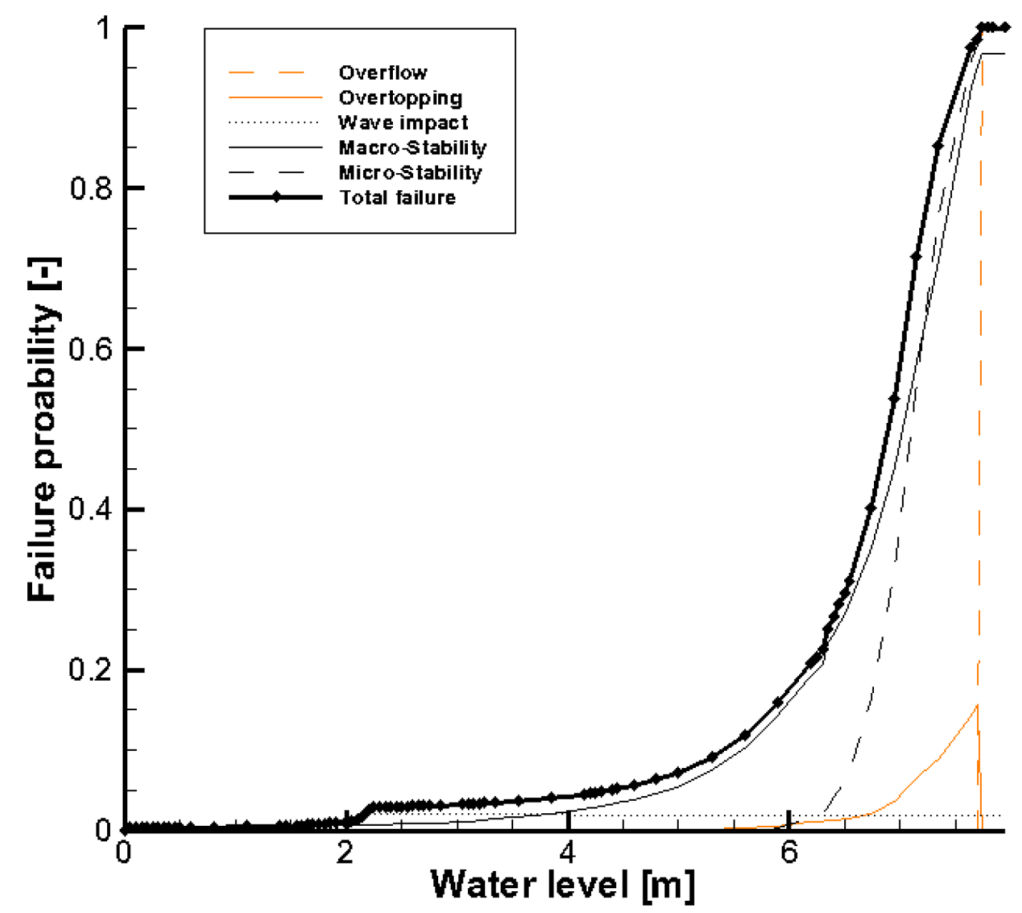

Figure 4: Fragility curve with total failure probability and segregated fragility curves for different failure mechanisms determined for the cross-section 29.9.

The last step is the calculation of the probability distributions propagation of the input variables to the probability of occurrence of the defined failure event [22]. Within the reliability analysis of ProMAIDes, this is performed with a Monte Carlo analysis applied to the described fault tree. A discrete fragility curve is finally generated by applying the Monte Carlo analysis for discrete water levels. More information about the calculation of fragility curves is provided by Bachmann [21].

The total fragility curve shows the probability of the occurrence of a failure event as a function of the water level, as shown in Fig. 4 for the specific cross-section 29.9 with the given input. In contrast to the total fragility curve, each mechanism is regarded separately by the determination of the segregated fragility curves. The segregated fragility curves provide information about the most critical failure mechanism for a dike section, allowing for interventions towards a specific direction. The calculated fragility curves for cross-section 29.9 (see Fig. 4) show that the dominant failure mechanisms are micro- and macro-stability of the landward slope. If the dike crest is reached (about $7.70 \mathrm{~m}$ ), than a failure due to an overflow event gets dominant. Wave impact and overtopping events have a minor influence on the total stability of the dike, whereas failure mechanisms that are not displayed have no influence.

\section{RESULTS AND DISCUSSION}

The two workflows of real-time assessment of dike strength and forecasting of probability of failure are implemented in the FEWS-DAM Live software system. 
Data of real-time water levels measured by the sensors are directly imported from the DDSC platform, whereas the forecast of the sea level is taken from the gauge station of Delfzijl. The location of each cross-section can be visualized in the map window (as shown in Fig. 1). Calculations of real-time safety factors and forecasted failure probabilities for the coming 48 hours are performed in continuous. In this way, it is possible to visualize for each cross-section the historical, current and future status of dike strength given the chosen input/ schematization. Selecting one or more locations, the software displays the water pressure measured by each sensor and the resulting safety factor in real-time together with the forecasted failure probabilities (total and segregated) based on the reliability transformation. It is possible to select individual failure mechanisms (e.g. macro-stability, wave impact) to analyse the influence of the single mechanisms on the total failure.

\subsection{Real-time assessment of dike strength}

Figure 5 shows the real-time stability assessment based on sensor data for cross-section 29.9. Moreover, the calculated total failure probability and the segregated failure probabilities for the mechanisms micro- and macro-stability of the landward slope are visualized. In the example provided the dike section is in a safe condition with a safety factor of 1.313 and an average total failure probability of $0.5 \%$.

The calculated data of dike stability give an indication of the strength/weakness of each cross-sections of the dike. Monitoring the dike stability provides thus useful information for the dike sections that do not satisfy the safety requirements until works of reinforcement are executed.

\subsection{Forecasting of dike strength}

Figure 6 shows an example of forecasting of dike strength based on a reliability transformation for cross-section 29.9. The total failure probability reaches a maximum of $0.4 \%$, which means that the dike section is in a safe state for the next 48 hours. Therefore, the dike does not require increased inspection or preparation measures for an emergency response.

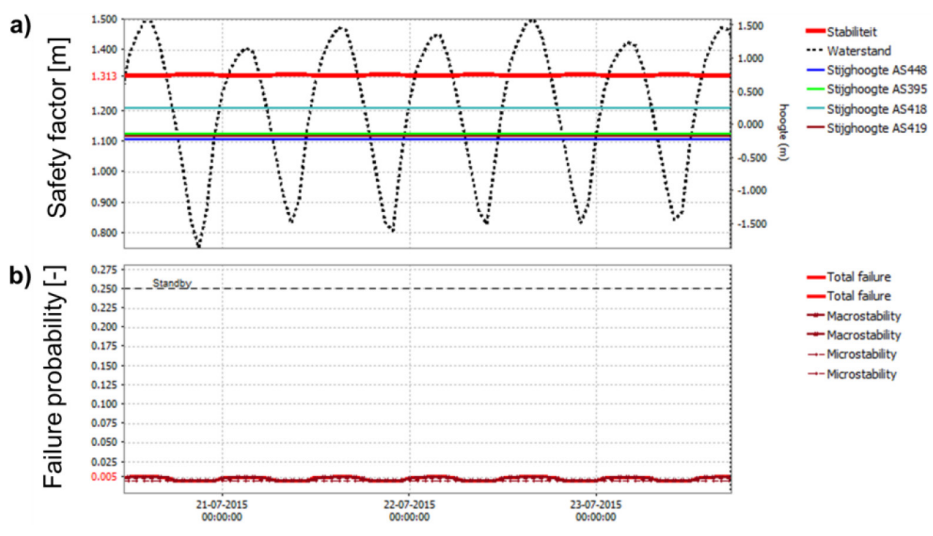

Figure 5: (a) Safety factor (red line), sea level (dotted line) and water levels measured by the sensors inside the dike section 29.9. (b) Failure probabilities for the same section. 


\subsection{Historical assessment of dike strength}

All the time series with measured and calculated values are stored in the DDSC server so that it is possible to visualize the full set of historical data. This is useful to identify and compare previous major events of high water levels. In case of a storm with predicted high values of failure probabilities, the analysis of previous events with the same magnitude allows for determining the consequences that the event could have on the dike.

Analysing the historical data of the Ommelanderzeedijk test case of the past years, a major storm surge event on 6 December 2013 was identified. During this event, a water level of 4.69 mNAP (Normal Amsterdam level) was observed at Delfzijl. Applying the reliability transformation to these historical values results in a total failure probability of about $40 \%$ for cross-section 33.4 (Fig. 7). As the dike did not collapse, this event can be used as a proof of strength of the dike.

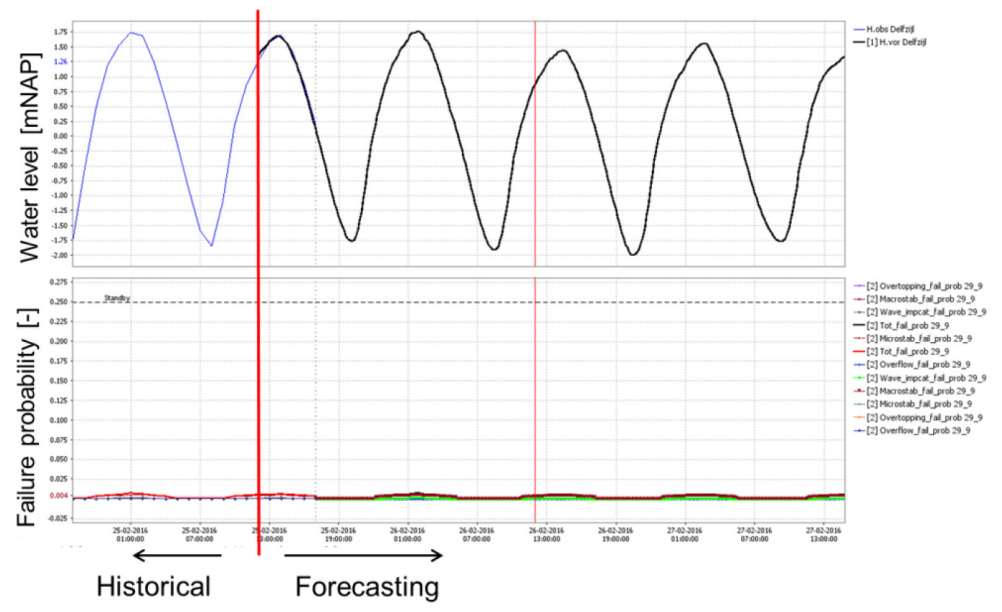

Figure 6: Forecasting of dike strength based on reliability transformation for cross-section 29.9.

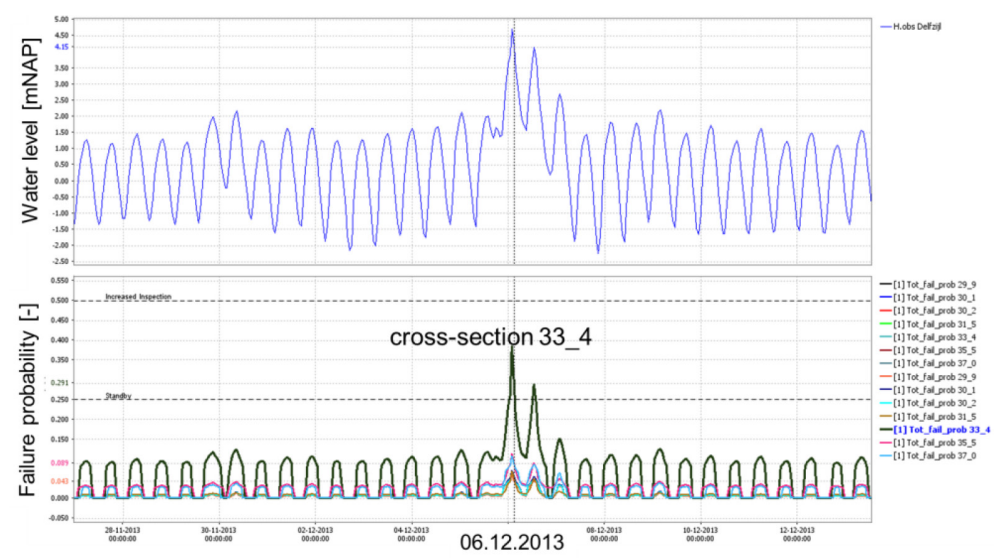

Figure 7: Historical assessment: a major storm surge event (above) and the corresponding failure probabilities of dike section 33.4 (below). 
Survived historical loadings are valuable information for the reliability of a flood defence that can be used to update the probability of failure [23]. This information is therefore crucial for decision-making in inspection, maintenance and emergency response planning.

\section{CONCLUSIONS}

FEWS-DAM Live is a software system that provides real-time monitoring and forecasting of dike strength. Along the Ommelanderzeedijk several cross-sections are equipped with sensors to transmit values of water levels in real-time. With the information of sensor data and subsoil schematization, stability calculations are performed to obtain a safety factor for each cross-section. The real-time assessment of dike strength is useful information for early warnings and to monitor weak sections of the dike before/after improvements.

Fragility curves are calculated for different failure mechanisms and combined with the imported forecast of water levels to derive the forecasted probability of failure of each cross-section of the dike for a period of 48 hours. It is thus possible to identify the precise time/location of failure and plan emergency measures.

The analysis of the historical database allows for identifying the dike response to the major storm surge events of the recent past. This provides useful information about the dike behaviour in critical conditions. Therefore, FEWS-DAM Live is a valuable tool to access information for the planning and intervention in both regular and emergency situations.

\section{ACKNOWLEDGEMENTS}

FEWS-DAM Live has been developed within the project LiveDijk XL Noorderzijlvest. The authors wish to thank Stichting FloodControl IJkdijk and Waterschap Noorderzijlvest. We thank Kin Sun Lam and Maya Sule of Deltares for the fruitful discussions in the development of this project.

\section{REFERENCES}

[1] Melnikova, N.B., Jordan, D. \& Krzhizhanovskaya, V.V., Experience of using FEM for real-time flood early warning systems: monitoring and modeling Boston levee instability. Journal of Computational Science, 10, pp. 13-25, 2015. http://dx.doi.org/10.1016/j.jocs.2015.04.033

[2] Melnikova, N.B., Jordan, D., Krzhizhanovskaya, V.V. \& Sloot, P., Numerical prediction of the IJkDijk trial embankment failure. Geotechnical Engineering, 168(2), pp. 158$171,2015$. http://dx.doi.org/10.1680/geng.14.00040

[3] Pyayt, A.L., Kozionov, A.P., Mokhov, I.I., Lang, B., Krzhizhanovskaya, V.V. \& Sloot, P.M.A., An approach for real-time levee health monitoring using signal processing methods. Procedia Computer Science, 18, pp. 2357-2366, 2013. http://dx.doi.org/10.1016/j.procs.2013.05.407

[4] Thielen, J., Bartholmes, J., Ramos, M.-H. \& de Roo, A., The european flood alert system - part 1: concept and development. Hydrology and Earth System Science, 13, pp. 125-140, 2009. http://dx.doi.org/10.5194/hess-13-125-2009

[5] Werner, M., Cranston, M., Harrison, T., Whitfield, D. \& Schellekens, J., Recent developments in operational flood forecasting in England, Wales and Scotland. Meteorological Applications, 16, pp. 13-22, 2009. http://dx.doi.org/10.1002/met.124 
[6] Roelevink, A., Udo, J., Koshinchanov, G. \& Balabanova, S., Flood forecasting system for the Maritsa and Tundzha Rivers. Conference Water Observation and Information System for Decision Support, Balwois 25-29 May 2010.

[7] Flood Control 2015, available at www.floodcontrol2015.com

[8] Dike Data Service Centre, available at www.openddsc.nl

[9] Bishop, A.W., The use of the slip circle in the stability analysis of slopes. Geotechnique, 5(1), pp. 7-17, 1955. http://dx.doi.org/10.1680/geot.1955.5.1.7

[10] USACE, Benefit determination involving existing levees. Memorandum for Major Subordinate Commands and District Commands, Policy Guidance Letter 26, Washington DC, 1991.

[11] Hall, J., Dawson, R., Sayers, P., Rosu, C., Chatterton, J.U. \& Deakin, R., A methodology for national-scale flood risk assessment. Water \& Maritime Engineering, 156(3), pp. 235-247, 2003.

http://dx.doi.org/10.1680/wame.2003.156.3.235

[12] Apel, H., Thieken, A.H., Merz, B. \& Bloschl, G., Flood risk assessment and associated uncertainty. Natural Hazards and Earth System Science, 4, pp. 295-308, 2004. http://dx.doi.org/10.5194/nhess-4-295-2004

[13] Dawson, R., Hall, J., Sayers, P., Bates, P.D. \& Rosu, C., Sampling-based flood risk analysis for fluvial dike systems. Stochastic Environmental Research and Risk Assessment, 19, pp. 388-402, 2005. http://dx.doi.org/10.1007/s00477-005-0010-9

[14] Simm, J.D., Gouldby, B.P., Sayers, P.B., Flikweert, J., Wersching, S. \& Bramley, M.E., Representing fragility of flood and coastal defences: getting into the detail. Flood Risk Management: Research and Practice, Taylor \& Francis Group: London, pp. 621-631, 2009.

[15] Van der Meer, J.W., ter Horst, W.L.A. \& van Velzen, E.H., Calculation of fragility curves for flood defence assets. Flood Risk Management: Research and Practice, Taylor \& Francis Group: London, pp. 567-573, 2009.

[16] Vorogushyn, S., Merz, B., Lindenschmidt, K.-E. \& Apel, H., A new methodology for flood hazard assessment considering dike breaches. Water Resources Research, 46, 2010.

http://dx.doi.org/10.1029/2009wr008475

[17] Bachmann, D. \& Schüttrumpf, H., Integration der Zuverlässigkeit von Hochwasserschutzbauwerken in die einzugsgebietsbasierte Hochwasserrisikoanalyse. Hydrology and Water Resources Management, 58(3), pp. 168-177, 2014.

[18] Diermanse, F.L.M., De Bruijn, K.M., Beckers, J.V.L. \& Kramer, N.L., Importance sampling for efficient modelling of hydraulic loads in the rhine-meuse delta. Stochastic Environmental Research and Risk Assessment, 29(3), pp. 637-652, 2015. http://dx.doi.org/10.1007/s00477-014-0921-4

[19] Schultz, M., Gouldby, B., Simm, J. \& Wibowo, J., Beyond the factor of safety: developing fragility curves to characterize system reliability. ERDC SR 10 1. G. a. S. Laboratory, USACE, 2010.

[20] Bachmann, D., Johann, G., Huber, N.P. \& Schüttrumpf, H., Fragility curves in operational dike reliability assessment. Georisk: Assessment and Management of Risk for Engineered Systems and Geohazards, 7(1), pp. 49-60, 2013.

http://dx.doi.org/10.1080/17499518.2013.767664 
[21] Bachmann, D., Beitrag zur Entwicklung eines Entscheidungsunterstützungssystems zur Bewertung und Planung von Hochwasserschutzmaßnahmen (Development of a decision support system for the assessment and design of flood mitigation measures). $P h D$ Thesis, Aachen: Institut für Wasserbau und Wasserwirtschaft, RWTH Aachen, http:// darwin.bth.rwth-aachen.de/opus3/volltexte/2012/4043/ [Accessed 31.01.2015], 2012.

[22] Merz, B., Hochwasserrisiken - Grenzen und Möglichkeiten der Risikoabschätzung, Schweizerbart'sche Verlagsbuchhandlung: Stuttgart, 2006.

[23] Schweckendiek, T., Reassessing reliability based on survived loads. Proceedings of the Coastal Engineering Conference, 32, 2010. 